\title{
Evidence that local dust sources supply low-elevation Antarctic regions
}

\author{
Bess G. Koffman ${ }^{1,2}$ and Karl J. Kreutz
}

\section{Dust flux and size distribution measurements from the West Antarctic Ice Sheet (WAIS) Divide and other non-East Antarctic plateau ice core sites suggest that local dust sources supply a significant amount of dust to the high-latitude atmosphere and ocean.}

Polar ice is an important high-latitude archive of past environmental and atmospheric changes. The physical measurement of dust particles trapped in well-dated ice cores provides independent information, in the form of dust flux and particle size distribution (PSD) parameters, about past environmental changes in dust source regions, the proximity of dust sources, and variability in atmospheric circulation intensity. Much effort has gone into understanding the sources and transport of dust to the high-elevation sites ( 3200-3500 m a.s.I.) Vostok and Dome C on the East Antarctic Ice Sheet (EAIS) plateau (Fig. 1). These records together provide a climatic history spanning the past eight glacial cycles (Lambert et al. 2008; Petit et al, 1999; Wolff et al. 2006). The East Antarctic plateau predominantly receives far-traveled dust, as evidenced by its lognormal distribution small size (mode of $2 \mu \mathrm{m}$ ) and geochemical signature (e.g. Basile et al. 1997; Delmonte et al. 2004). The ice cores from this region provide invaluable information about hem ispheric-scale changes in dust emissions and transport, but due to their high altitude, they do not capture dust carried in the lower-to-middle troposphere, and thus do not represent dust delivery to about half the Antarctic continent.

In order to assess changes in dust supply and transport to the lower-elevation regions of Antarctica, we must look to ice core records from West Antarctica and around the margins of the EAIS. Dust flux and particle size distribution measurements from WAIS Divide and other lower-elevation and coastal cores show that these sites receive both higher dust fluxes and coarser PSDs than the East Antarctic plateau cores. Accordingly, we infer that local dust sources supply a significant amount of dust to the atmosphere and ocean around Antarctica.

\section{Higher dust fluxes near}

\section{the Antarctic coast}

Dust flux is measured in units of mass per area and time. It takes into account the possible dilution effects of the snow accumulation rate on aerosol deposition, and thus can be compared readily among sites and across time intervals. Changes in dust flux are considered to represent changes in atmospheric dust concentrations
(Fischer et al. 2007; Wolff et al. 2006); therefore, flux measurements offer insight into the atmospheric dust burden and its potential impacts on climate.

During the late Holocene, dust fluxes measured at sites near the margins of the Antarctic ice sheet and at elevations below $2500 \mathrm{~m}$ a.s.l. range from about 1-12 $\mathrm{mg} \mathrm{m}^{-2} \mathrm{yr}^{-1}$ (Fig. 2). This contrasts with the significantly lower fluxes well below $1 \mathrm{mg} \mathrm{m}^{-2} \mathrm{yr}^{-1}$ measured at high-elevation East Antarctic sites. At WAIS Divide a background dust flux of $\sim 3-5 \mathrm{mg} \mathrm{m}^{-2} \mathrm{yr}^{-1}$ is punctuated by several particularly dusty intervals during the last two millennia, reaching peak fluxes of $\sim 15-25 \mathrm{mg} \mathrm{m}^{-2} \mathrm{y}^{\mathrm{r}-1}$ (Koffman et al. 2014). At James Ross Island near the tip of the Antarctic Peninsula (1540 $\mathrm{m}$ a.s.l.), dust flux (calculated using aluminum concentrations) was found to be $12 \mathrm{mg} \mathrm{m}^{-2} \mathrm{yr}^{-1} \mathrm{ca} .150$ years ago, prior to the effects of land-use changes in Patagonia (McConnell et al. 2007). Near the Transantarctic Mountains at $2315 \mathrm{~m}$ a.s.I., the Talos Dome ice core yields a late Holocene dust flux of about $1 \mathrm{mg}$ $\mathrm{m}^{-2} \mathrm{yr}^{-1}$ (Albani et al. 2012). While these records come from different sectors of the Antarctic continent and are almost undoubtedly influenced by different dust sources, they consistently show dust fluxes substantially higher than those seen on the East Antarctic plateau, where the interglacial dust flux is $0.2-0.6 \mathrm{mg} \mathrm{m}^{-2} \mathrm{yr}^{-1}$ (Lambert et al. 2012). Corroborating these observations, Bory et al. (2010) report that the dust flux measured in modern snow at Berkner Island (899 $\mathrm{m}$ a.s.l.) in the Weddell Sea is about three times higher than at Kohnen Station in Dronning Maud Land (DML; $2890 \mathrm{~m}$ a.s.l.) for particles in the 5-10 $\mu \mathrm{m}$ range. Similarly, nss Ca ${ }^{2+}$ fluxes (a common proxy for mineral dust in ice cores) measured in the EPICA (European Project for Ice Coring in Antarctica) DML ice core at Kohnen Station were found to be three times higher than those measured at Dome C, which is about $300 \mathrm{~m}$ higher and several thousand $\mathrm{km}$ further from Patagonian dust sources (Fischer et al. 2007). In short, during the late Holocene, sites from Antarctica show an inverse relationship between elevation and dust flux (Fig. 2).

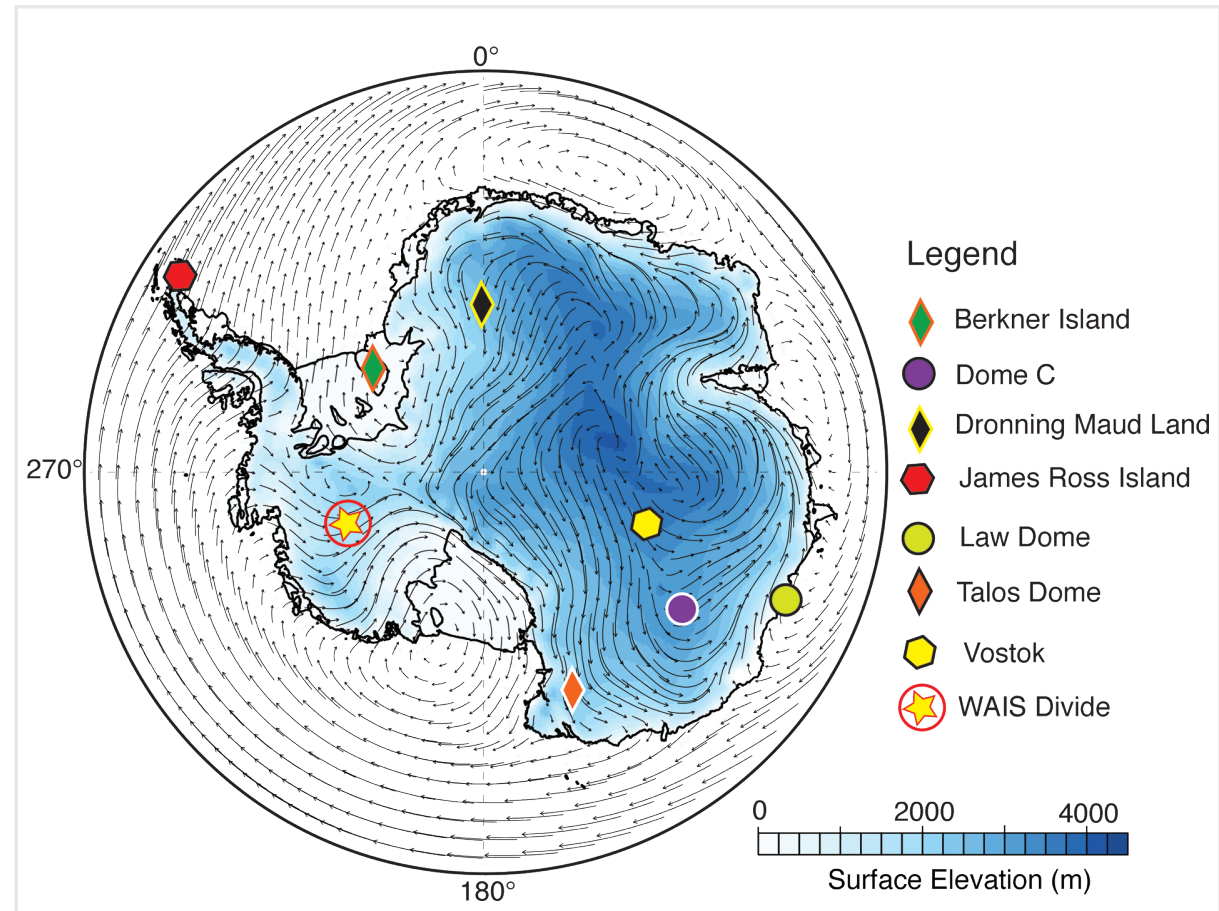

Figure 1: Surface elevation map of Antarctica showing sites discussed in the text and annual average winds at 700 hPa (ERA-Interim climate reanalysis). Image obtained using Climate Reanalyzer (http://cci-reanalyzer.org). 


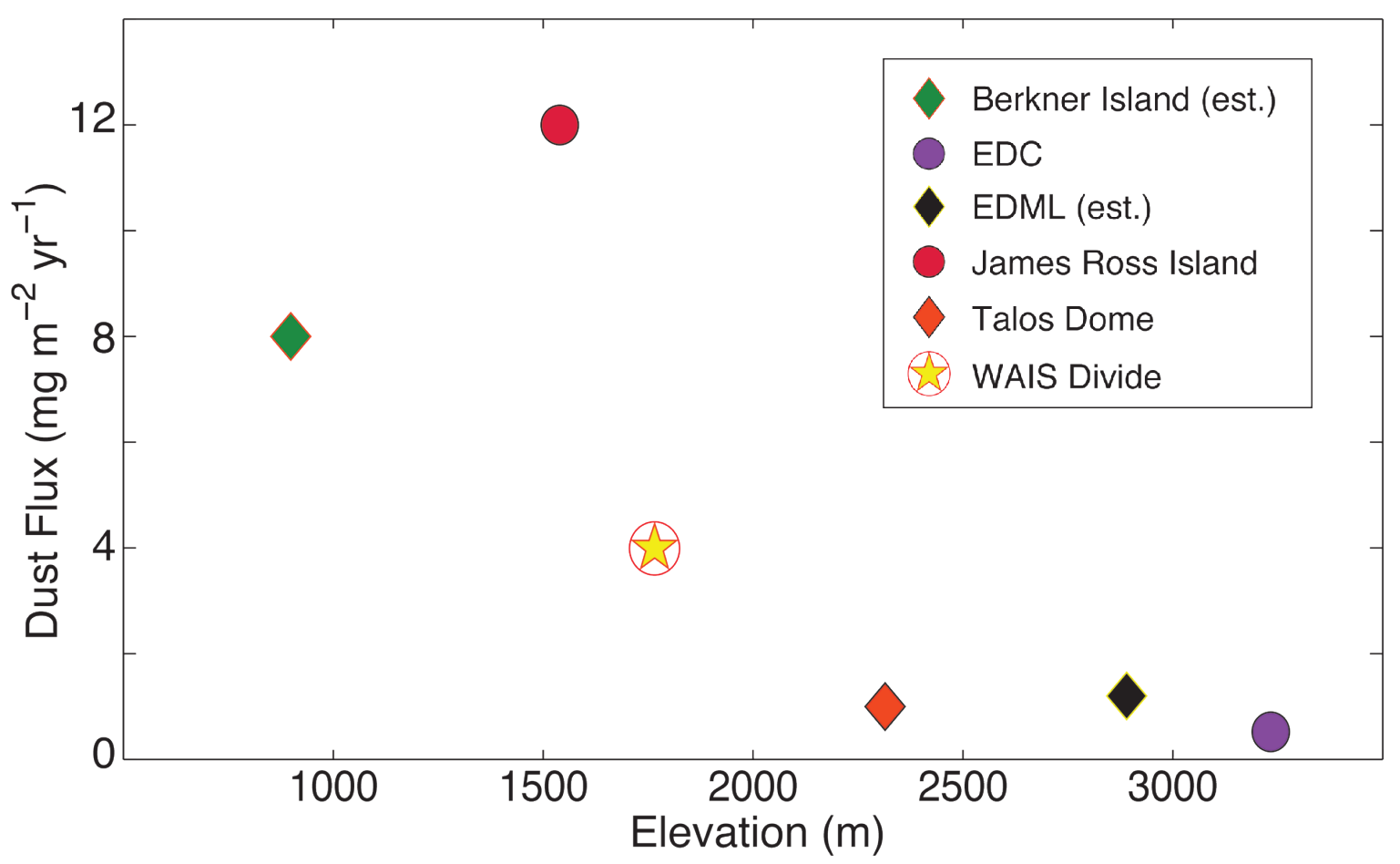

Figure 2: Dust flux versus elevation for: Berkner Island (Bory et al. 2010), EPICA Dome C (EDC; Lambert et al. 2012), EPICA Dronning Maud Land (EDML; Fischer et al. 2007), James Ross Island (McConnell et al. 2007), Talos Dome (Albani et al. 2012) and WAIS Divide (Koffman et al. 2014). Flux values for EDML and Berkner Island are estimated based on published flux ratios to other sites and available particle size information.

These observations imply an elevational gradient in the atmospheric dust burden over Antarctica, with the ice sheet margins receiving about 1-2 orders of magnitude more dust than the East Antarctic plateau. Further supporting evidence comes from high and low iron flux measurements from coastal Law Dome and high-elevation Dome $C$ in East Antarctica, respectively (Edwards et al. 2006). Observation of an elevational dust flux gradient within the EAIS confirms that observed flux differences across Antarctica do not relate to regional (e.g. WAIS vs. EAIS) differences. Instead, it seems likely that the higher fluxes at coastal sites and below $\sim 2500$ m elevation reflect greater proximal dust emissions activity, and possibly also higher deposition of far-traveled dust (e.g. from Patagonia and Australia). Today, about $2 \%$ of Antarctica is ice-free, comprising an area roughly the size of New Zealand (Campbell and Claridge 1987). Although much of this area consists of exposed bedrock, several regions with available fine-grained material could serve as dust sources.

\section{Coarse particles imply local sources}

Coarser particle sizes near the margin of the Antarctic ice sheet and at elevations below $2500 \mathrm{~m}$ a.s.l. further support that proximal dust sources play an important role. At WAIS Divide, the dust flux is dominated by particles in the 5-10 $\mu \mathrm{m}$ range, and the long-term (100 year average) mode size of the volume-weighted distribution is 5-8 $\mu \mathrm{m}$ diameter (Koffman et al. 2013). From the few sites in Antarctica where mode sizes have been reported, it appears that relatively coarse PSDs are a common feature of lower-elevation regions. For example, late Holocene dust deposited at Berkner Island and at Talos Dome is dominated by particles $>5 \mu \mathrm{m}$ diameter (Albani et al. 2012; Bory et al. 2010). The high proportion of coarse particles contrasts with observations from the East Antarctic plateau, where the volume-weighted mode size is close to $2 \mu \mathrm{m}$ diameter for both glacial and interglacial periods (Delmonte et al. 2002). Although very coarse (> $75 \mu \mathrm{m}$ diameter) particles have been observed to travel distances greater than 10,000 km (Betzer et al. 1988), particles larger than $5 \mu \mathrm{m}$ diameter generally are associated with short transport distances (e.g. Mahowald et al. 2013; Tegen and Lacis 1996), implying local sources of dust.

\section{Conclusions}

The observed differences in dust fluxes and PSDs between lower- and higher-elevation sites in Antarctica (e.g. below or above $2500 \mathrm{~m}$ a.s.l.) indicate that locally sourced dust is transported too low to reach the East Antarctic plateau. Climate models suggest that dust originating from southern South America and Australia is transported at altitudes greater than 4000 m (Krinner et al. 2010), i.e. well above the Vostok and Dome C ice core sites (e.g. Basile et al. 1997; Delmonte et al. 2004; Revel-Rolland et al. 2006). In contrast, based on existing particle size measurements, we infer that dust from Antarctic ice-free areas is transported below $\sim 2500$ $\mathrm{m}$. Additional PSD measurements from a range of elevations are needed to confirm this interpretation.

The relatively coarse PSDs at WAIS Divide and other sites below $2500 \mathrm{~m}$ a.s.I. are good evidence that Antarctic ice-free areas comprise active dust sources for the high-latitude atmosphere and ocean.
While some areas, such as the McMurdo Dry Valleys, are known to be dusty (e.g. Bory et al. 2010), additional work is needed to understand the emissions activity and importance of Antarctic potential dust source areas, including the relative contributions of glacier-derived sediments and material of volcanic origin.

\section{ACKNOWLEDGEMENTS}

This research was supported by NSF ANT-0636740 and ANT-1204050, and by the University of Maine Chase Distinguished Research Assistantship, Correll Graduate Student Research Fellowship, and Dissertation Research Fellowship to B.G.K.

\section{DATA}

The WAIS Divide ice core dust record can be obtained from the Global Change Master Directory (GCMD) public database.

\section{AFFILIATIONS}

${ }^{1}$ School of Earth and Climate Sciences and the Climate Change Institute, University of Maine, Orono, USA ${ }^{2}$ Lamont-Doherty Earth Observatory of Columbia University, Palisades, USA

\section{CONTACT}

Bess G. Koffman: bkoffman@ldeo.columbia.edu REFERENCES

Full reference list under:

www.pages-igbp.org/products/magazine/ref2014_2.pdf Albani S et al. (2012) Clim Past 8: 741-750

Bory AJ-M et al. (2010) Earth Planet Sci Lett 291: 138-148 Delmonte B et al. (2004) Earth Sci Rev 66: 63-87 Koffman BG et al. (2014) Clim Past 10: 1-20 Lambert F et al. (2012) Clim Past 8: 609-623 